\title{
Transmission Electron Microscopy of Martensitic Phase Transformations in Ni-Mn-Ga Ferromagnetic Shape Memory Alloys
}

\author{
J.C. Bennett*, C.V. Hyatt**, M.A. Gharghouri***, S. Farrell**, M. Robertson*, G. Pirge** and \\ J. Chen*** \\ *Dept. of Physics, Acadia University, Wolfville, Nova Scotia, Canada B0P 1X0 \\ **Defence R\&D Canada-Atlantic, P.O. Box 99000, Stn. Forces, Halifax, N.S., Canada, B3K 5X5 \\ *** Dept. of Mining and Metallurgical Engineering, Dalhousie University, Halifax, N.S., Canada, \\ B3J 2 X4
}

$\mathrm{Ni}-\mathrm{Mn}-\mathrm{Ga}$ ferromagnetic shape memory alloys are a new class of actuator materials which develop large strains when exposed to a magnetic field [1]. The strains result from a magnetic field induced reorientation of the twin variants in the martensitic phase. The phenomenon combines the advantageous aspects of traditional magnetostriction (its frequency limit) and conventional shape memory effects (strains up to 10\% [2]). As a result, these alloys offer an important new avenue for producing force and motion in many engineering applications.

Oriented polycrystalline boules having the nominal compositions listed in Table 1 were grown by a seedless Bridgman method with directional solidification. Thin foils were prepared by twin-jet electropolishing with a $33 \% \mathrm{HNO}_{3} /$ methanol electrolyte at $10 \mathrm{~V}$ and $240 \mathrm{~K}$. A Philips EM301 TEM $(100 \mathrm{kV})$ equipped with a double-tilt heating and cooling stage was used for in situ studies while high resolution imaging at room temperature was carried out with a JEOL 2010 TEM operated at $200 \mathrm{kV}$.

For Alloy 1, electron diffraction indicated that the Heusler ordered (L2 1 ) parent phase was present at room temperature (Fig 1a). Characteristic "tweed" strain contrast, which has previously been attributed to pretransitional phonon softening in stoichiometric $\mathrm{Ni}_{2} \mathrm{MnGa}$ [3], was evident and HREM images (Fig. 1b) showed substantial perturbation of the Heusler order on a length scale of 10-20 lattice constants. The diffuse streaking observed in the diffraction patterns at room temperature gradually increased and sharpened on cooling. Well-defined satellites of the intermediate phase appeared along these streaks at roughly $200 \mathrm{~K}$ (Fig. 1c), prior to transformation at $190 \mathrm{~K}$ to a martensitic structure with a lattice modulation period of typically 7 atomic layers (Fig. 1d).

Alloys 2 and 3 behaved similiarly with the L2 1 parent phase, exhibiting anomalous tweed contrast, and 5-layer martensite being intermixed in thin foils examined at room temperature (Fig. 2a). On heating, the 5-layer martensite appears to transform directly to the austenite parent at $\sim 310 \mathrm{~K}$ (Fig. $2 \mathrm{~b}, \mathrm{c})$, in agreement with earlier results of Chernenko et al. [4] who suggested that the dynamical instability driving the formation of the intermediate phase is competitive with, rather than precursor to, the martensitic transformation.

\section{References:}

[1] K. Ullakko, J.K. Huang, C. Kantner and R.C. O’Handley, Appl. Phys. Lett. 69 (1996) 1966. [2] A. Sozinov, A.A. Likhachev, N. Lanska and K. Ullakko, Appl. Phys. Lett, 80 (2002) 1746.

[3] A. Zheludev, S.M. Shapiro, P. Wochner, A. Schwartz and L.E. Tanner, Phys. Rev. B51 (1995) 11310.

[4] V.A. Chernenko, J. Pons, C. Segui and E. Cesari, Acta Mater. 50 (2002) 53. 
Table 1: Alloy compositions and measured transformation temperatures

\begin{tabular}{|c|c|c|c|c|c|c|}
\hline Alloy & Ni (at. \%) & Mn (at. \%) & Ga (at. \%) & Electron/atom & $\mathrm{T}_{\text {Mart-start }}(\mathrm{K})$ & $\mathrm{T}_{\text {Aust-start }}(\mathrm{K})$ \\
\hline 1 & 50.1 & 28.2 & 21.7 & 7.64 & 190 & 210 \\
\hline 2 & 49.3 & 28.6 & 22.1 & 7.60 & 310 & 318 \\
\hline 3 & 49.8 & 28.3 & 21.6 & 7.61 & 303 & 313 \\
\hline
\end{tabular}
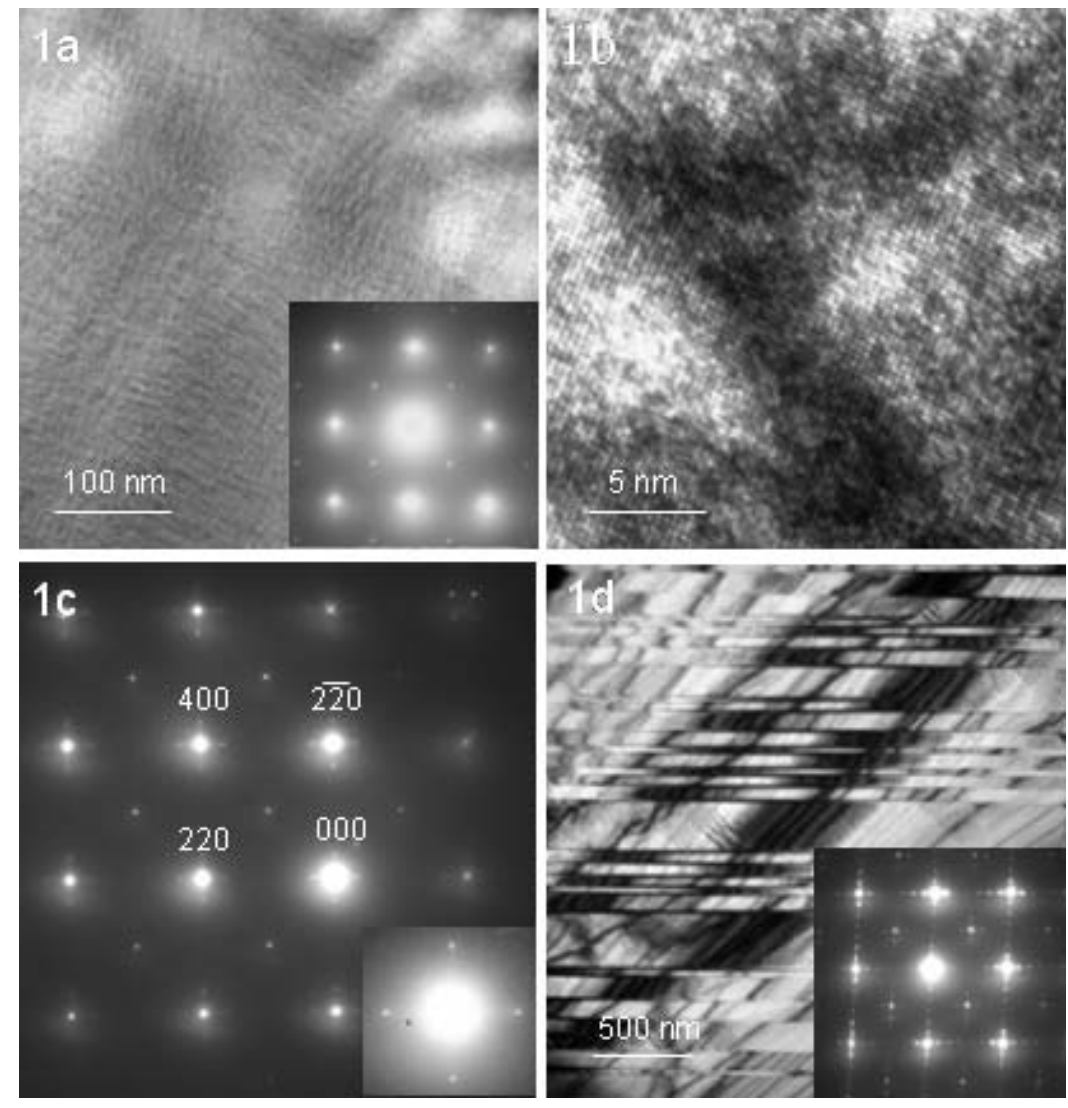

Fig. 1 (a) BF image of Alloy 1 showing "tweed" strain contrast. Inset: [100] aust zone axis edp at 295 K. (b) Corresponding HREM image. (c) [100 $]_{\mathrm{L} 21}$ zone axis edp at $198 \mathrm{~K}$. Inset: (000) reflection and surrounding $1 / 6<110>_{\mathrm{L}_{2}}$ satellites. (d) $\mathrm{BF}$ image at $175 \mathrm{~K}$ showing 7-layer martensite plates with corresponding edp inset.
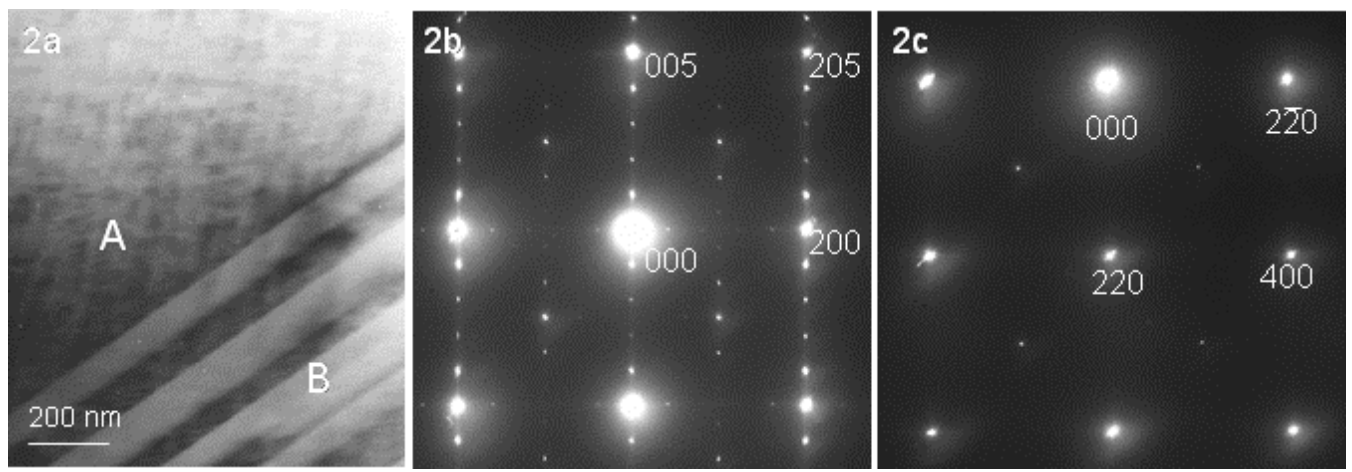

Fig. 2 (a) BF image of Alloy 3 at $295 \mathrm{~K}$ showing "tweed" (region A) and 5-layer martensite (B). Edps from region $\mathrm{B}$ at (b) $295 \mathrm{~K}$ and (c) $313 \mathrm{~K}$, indexed for 5-layer martensite and $\mathrm{L} 2{ }_{1}$ ordered austenite. 